\title{
BMJ Open Phenomenological approach to childhood cataract treatment in New Zealand using semi-structured interviews: how might we improve provision of care
}

\author{
Lisa M Hamm, ${ }^{1}$ Karla A Boluk, ${ }^{2}$ Joanna M Black, ${ }^{1}$ Shuan Dai, ${ }^{3}$ \\ Benjamin Thompson ${ }^{1,4}$
}

To cite: Hamm LM,

Boluk KA, Black JM, et al. Phenomenological approach to childhood cataract treatment in New Zealand using semi-structured interviews: how might we improve provision of care. BMJ Open 2019;9:e024869. doi:10.1136/ bmjopen-2018-024869

\section{- Prepublication history for} this paper is available online. To view these files, please visit the journal online (http://dx.doi org/10.1136/bmjopen-2018024869).

Received 29 June 2018 Revised 24 October 2018 Accepted 5 November 2018

Check for updates

(c) Author(s) (or their employer(s)) 2019. Re-use permitted under CC BY-NC. No commercial re-use. See rights and permissions. Published by BMJ.

${ }^{1}$ School of Optometry and Vision Science, The University of Auckland, Auckland, New Zealand

${ }^{2}$ Department of Recreation and Leisure Studies, University of Waterloo, Waterloo, Ontario, Canada

${ }^{3}$ Department of Ophthalmology, The University of Auckland, Auckland, New Zealand

${ }^{4}$ School of Optometry and Vision Science, University of Waterloo, Ontario, Canada

Correspondence to

Dr Lisa M Hamm;

I.hamm@auckland.ac.nz

\section{ABSTRACT}

Purpose To understand how we might improve the provision of medical care for children with cataracts. Design A phenomenological design was employed. Semistructured interviews were conducted to capture rich descriptions of the phenomena. Our goal in the interview and the analysis was to understand the sources of distress associated with treatment for cataract and deprivation amblyopia which (1) could be addressed by the medical community and (2) related to treatment adherence. Setting Interviews were conducted by a non-clinician researcher in New Zealand (NZ) in a location chosen by informants. In NZ, the red reflex screening test is performed shortly after birth, and surgery to remove paediatric cataracts is publicly funded.

Participants Families of children who had a history of cataract in Auckland, NZ were posted an invitation to participate. Twenty families were interviewed.

Results Our analysis illustrated that informants described a wide range of experiences, from declined cataract surgery to full adherence to medical advice including years of patching for more than 4 hours a day. Across these experiences, we identified three relevant themes; timing of diagnosis, communication between the parent and clinician, and parental social support networks.

Conclusion The medical community may be better placed to support families dealing with childhood cataract by improving detection of childhood cataract, building appropriate communication pathways and promoting social support, with an emphasis on empathetic, individualised care.

\section{INTRODUCTION}

Elimination of visual impairment from childhood cataract is one of the key objectives of the VISION 2020 initiative. ${ }^{12}$ The removal of the opaque lenses preventing a child from seeing requires specialised expertise, surgical facilities and various consumables, at an estimated base cost of approximately US $\$ 300^{3-5}$ in low-income and middle-income countries and an estimated US\$5000 in developed

\section{Strengths and limitations of this study}

- Informants had a broad range of experiences, from very positive to very negative, likely to reflect the diversity of the cohort of interest.

- Data from interviews were rich and themes converged across diverse experiences.

- The impact of culture was not a specific focus of the interviews. Our iterative analysis indicated that cultural factors may enhance understanding of families' experiences. This is recommended as an area of further research.

- The authors are generally invested in adherence with ophthalmological recommendations. This bias is clearly stated in our purpose.

countries such as NewZealand (NZ). Although childhood cataracts are rare (impacting approximately 2.5 in 10000 children $^{6}$ ), the investment in treatment is advocated for globally due to the resulting improvements in quality of life ${ }^{7}$ and long-term economic benefits. ${ }^{4}$ Given the impact, removal of childhood cataracts is prioritised, with many non-governmental organisations (NGOs) supporting communities unable to make this investment. ${ }^{8-10}$ Despite NGO support, disparities exist, with childhood cataract accounting for approximately $20 \%-30 \%$ of childhood blindness in lower income areas, ${ }^{11} 12$ and closer to $5 \%{ }^{13}$ in higher income countries. ${ }^{14}$

However, the vision loss associated with bilateral or unilateral paediatric cataract is not fully resolved with surgical removal of the opaque lens (for overviews see refs 15-17). The cataract needs to be identified and appropriate referrals made. ${ }^{18} 19$ A replacement lens needs to be implanted, or compensatory contact lens or spectacle correction prescribed. ${ }^{15}$ Children often require follow-up 
surgeries and ongoing assessment of appropriate refraction. ${ }^{15}$ Furthermore, there is a risk of secondary conditions, such as glaucoma ${ }^{20}$ and the risk of deprivation amblyopia increases sharply if the cataract is not removed shortly after onset. ${ }^{21} 22$ Deprivation amblyopia is abnormal visual cortex development caused by visual deprivation, typically by a cataract, in one or both eyes early in life. ${ }^{23}$ Deprivation amblyopia leads to long-lasting visual impairment that persists after cataract removal. ${ }^{23}$ The impact of deprivation amblyopia on the more basic aspects of vision (contrast sensitivity and visual acuity) of the affected eye(s) is more pronounced following unilateral ${ }^{22}$ than bilateral $^{21}$ cataract, although the symptoms are varied and dependent on the duration of visual deprivation. ${ }^{24}$ The treatment for amblyopia involves occlusion (patching) or penalisation (atropine cycloplegia) of the stronger eye to promote use of the weaker eye. ${ }^{23}$ These are home-based therapies which can be difficult for families to implement. ${ }^{25}$ Taken together, the efficacy of childhood cataract surgery is affected by a range of factors including early detection, prompt uptake of surgical intervention and dedicated commitment to follow-up care by the family and medical community (for discussion see refs 1526 ).

Each step in the treatment pathway for childhood cataract has been investigated, including screening, ${ }^{19}$ 27-30 factors contributing to delayed utilisation of surgical services, ${ }^{31}$ parental stress associated with childhood cataract treatment, ${ }^{32} 33$ compliance with amblyopia treatment ${ }^{34-38}$ and the impact of cataract removal on quality of life. ${ }^{79}$ Across this international body of work, the services that are available, affordable and accepted by the community being studied vary considerably. Studies of social barriers to accessing care, delayed cataract removal and poor follow-up tend to be done in lower income countries, 7193140 whereas research into issues such as increasing adherence with amblyopia treatment tend to cluster in higher income countries. ${ }^{25}$ 34-37 The research generally reflects the predominant hierarchical needs within communities. ${ }^{41}$ However, socioeconomic disparities exist within even high-income countries and there is growing recognition that wider research is needed to allow the best visual outcomes for all children. ${ }^{3841}$

In this study, we were interested in the experience of childhood cataract in Auckland, NZ, where ethnicity is diverse (67\% European, 15\% Maori, 11\% other, $9 \%$ Asian, $7 \%$ Pacific Peoples, 1\% Middle Eastern/Latin American/ Africa-from 2006 census data), and advanced ophthalmological services are now well established and publicly funded. In the early 1970s, cataract accounted for $22.5 \%$ of the children registered as blind in NZ, ${ }^{42}$ whereas a more recent report indicates substantial improvements in the treatment of childhood cataract, with only approximately $4 \%$ of children experiencing blindness or low vision attributed to childhood cataract. ${ }^{43}$ There is likely further room for improvement, with a recent report suggesting detection of childhood cataract is suboptimal. ${ }^{30}$ There is no published research in NZ about adherence with follow-up or the extent of secondary amblyopia following childhood cataract surgery. In the current study, we aimed to understand how childhood cataract and its treatment impacted NZ families, as a starting point to address potential gaps in the system. A qualitative study in the USA found that 'treatment' itself was one of six key themes decreasing quality of life for children with a history of cataracts. ${ }^{39}$ Our project probes this idea by focusing on families' lived experience (phenomenology) throughout the treatment pathway. Our aim was to identify sources of distress which (1) could be addressed by the medical community and (2) related to adherence with recommendations from their ophthalmologist.

\section{METHODOLOGY \\ Study context}

The study was conducted in Auckland, NZ, where comprehensive childhood vision screening systems are in place (red reflex examination at birth and at the 6-week check, pre and in school acuity checks) specialised paediatric cataract surgery is publicly funded and prioritised, and subsidies are available for refractive correction, occlusion therapy and transportation costs for families who require financial assistance and/or have particularly high visual needs. The study cohort was culturally diverse (reflecting national averages) and approximately one-third had lived and received medical advice outside of NZ. The first author carried out the semi-structured interviews. This author is a non-clinical researcher (not involved in any of the participant's care), and it was made clear to all informants that participation in the study would not impact the care they received.

\section{Patient and public involvement}

This project was a first step towards understanding how the medical community could improve provision of treatment for childhood cataract. The project was part of a larger study about the consequences of, ${ }^{44}$ and potential for rehabilitation after ${ }^{45}$ visual deprivation due to childhood cataract. A lay summary of results will be available to all participants, and information will also be disseminated at a community follow-up meeting or 'hui'.

\section{Participant recruitment}

In phenomenological studies, a purposive sampling strategy is supported in order to recruit participants who have experienced the phenomenon under study. ${ }^{46}$ Accordingly, research participants were intentionally contacted following a medical records search. Inclusion criteria included history of a visually significant paediatric cataract (congenital, developmental and traumatic cases) and current age between 4 and 20 years. Exclusion criteria included severe developmental disorders or severe ocular disease unrelated to paediatric cataract, noted on ophthalmological records. Invitation letters were posted to 39 parents resulting in 17 positive responses, each of whom was invited to participate in the study, including one parent of a non-verbal child with autism (autism was 
not diagnosed at the time of cataract surgery). One additional family made contact independently; their son had not had surgery to remove his cataract. Two additional families were made aware of the project through their specialist. A total of 20 semi-structured interviews were carried out.

\section{Semi-structured interviews}

Interviewing is the primary data collection strategy in phenomenological studies. ${ }^{46}$ As such, semi-structured interviews were employed focussing on the lived experiences and personal perceptions of the treatment process for childhood cataract and secondary deprivation amblyopia. Interviews were conducted in a private location of the participant's choice and audio recorded (except in one case due to excessive background noise). We requested that both caregivers and the affected child were present, and we encouraged all attendees to contribute to the conversation. Interviews were approximately 1 hour in length for each family, but varied in an attempt to obtain rich data. Semi-structured interviews were transcribed by the first author. Potentially identifiable information was removed or anonymised, and pseudonyms were assigned (pseudonyms reflect most common NZ names for birth year). The approximate timing of key treatment events was derived from each interview (narrative summary) and used to provide context for understanding phenomenology (lived experience).

\section{Phenomenology}

Phenomenology is a qualitative data analysis strategy used in various fields as a tool to delve into personal lived experience. ${ }^{47-49}$ This approach is particularly important for childhood medical research, in which parental choices impact childhood health outcomes and these choices exist within a complex context. Our primary goal was to develop an in-depth appreciation of each family's experience of childhood cataract treatment. We felt this goal was best addressed by a descriptive phenomenological approach.

Husserl's ${ }^{47}$ approach to phenomenology, as made explicit by Giorgi, ${ }^{48}$ and summarised by Wertz ${ }^{49}$ includes four steps, which we carried out as follows: (1) Open reading: we attempted to understand each experience as a whole; (2) Meaning units: we divided each transcript into units of meaning or 'themes'; (3) Psychological reflection: we reflected on the relevance of the themes to our research interest, and how they related to each other. This was an iterative process including rereading, summarising, grouping together and redefining meaning units to better reflect informant experience. Finally, (4) Structural understanding and description: we consolidated relevant emergent ideas, which we present as three themes and seven sub themes. The first and second author mutually carried out an analysis of the transcripts and then compared notes which resulted in the final presentation of themes. We used Standards for Reporting
Qualitative Research reporting guidelines for qualitative research. ${ }^{50}$

Research questions are approached from the frame of our own experiences. As authors, our framing included that (1) we trusted the evidence suggesting that prompt removal of cataracts and adherence with amblyopia treatments (such as patching) are in the best interest of the child and (2) a critique of family's responses to a challenging life event was outside our scope. We structured our research question to highlight our perspective rather than bracketing our experience from our interpretation; we focused on what the medical community could do to alleviate distress, particularly in ways that could promote adherence. In the process of seeking to find meaning across the experiences of our informants, we tended towards a constructivist epistemology; fundamentally believing that meaning is constructed rather than discovered. Through iteration, we understood our constructed meaning to be best exemplified in terms of negative and positive experiences of the emergent themes. Therefore, the themes presented reflect encouragement to families at their best and exasperated distress at their worst.

\section{RESULTS}

\section{Narrative summary}

Informants had a wide range of experiences. Key treatment events are summarised as cataract diagnosis, cataract removal, refractive correction and amblyopia treatment. Timelines for each participant are presented in figure 1, based on estimates from interview data. Some participants had congenital cataracts which were present at birth, others had cataracts which were detected or developed during early childhood, and others had traumatic cataracts resulting from an eye injury. It is of note that some parents were unsure whether their child had congenital or developmental cataracts.

There were no cases in which availability of surgery after diagnosis limited care, however, perception of delayed detection of cataract was an important issue raised. For one child (Riley), parents were told cataract removal would have too poor a prognosis to justify surgery, given the delay in diagnosis. We have expanded on delays in diagnosis in the first theme. Unlike most families who prioritised prompt cataract removal, Emily and Benjamin's families both declined surgery initially. Both later took up the services, phenomena we further explore within the second and third themes.

The experience with home implementation of follow-up treatment was diverse. Although no families noted cost of glasses, contacts or patches to be prohibitive, parents expressed concern that acquiring these items and navigating subsidies was complicated and could be stressful. For those who used glasses, feedback was very positive, except for the one participant prescribed glasses in her teenage years (Georgia), who felt uneasy with the aesthetic aspects of wear. Only children with very early surgery used contact lenses instead of an intraocular lens 


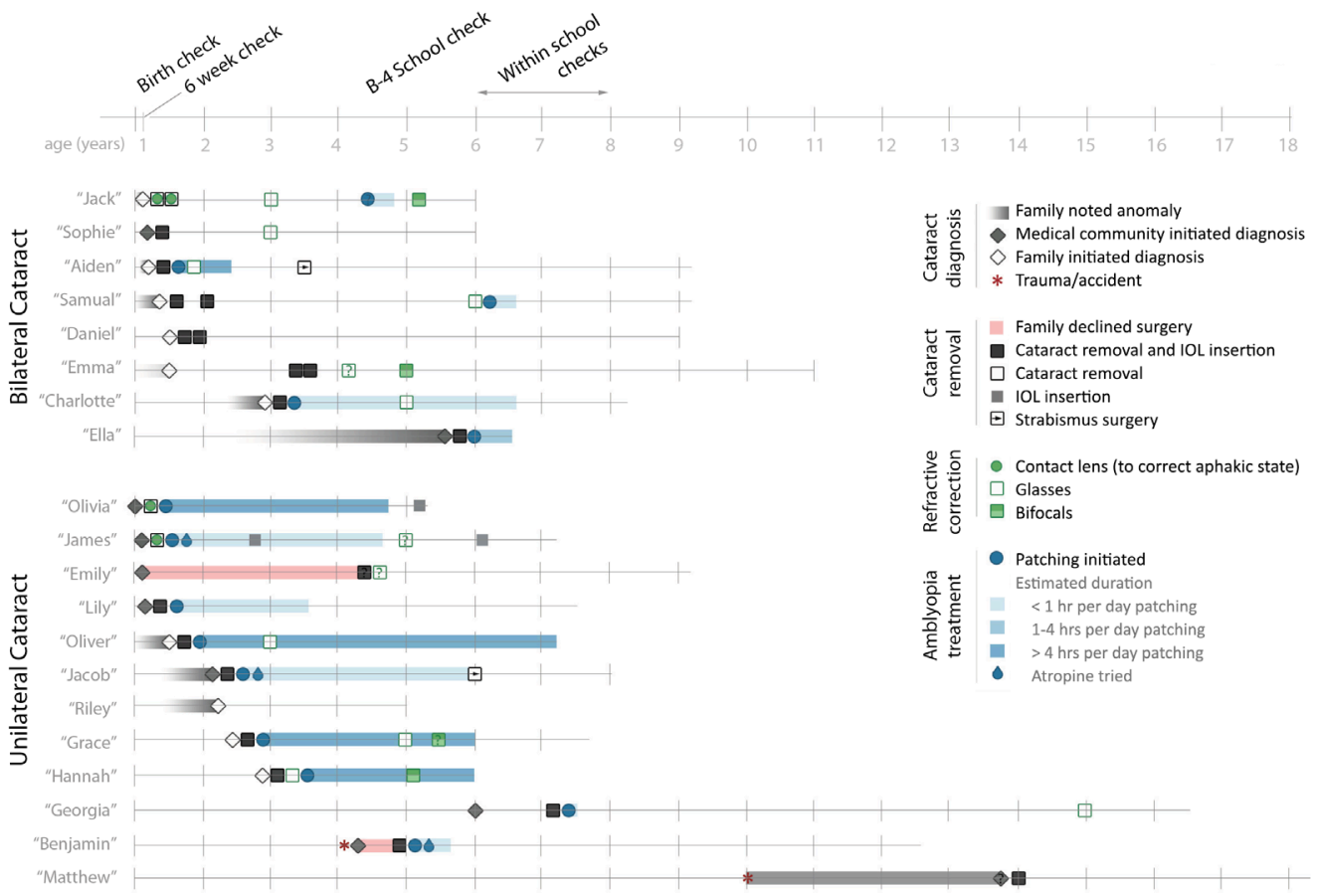

Figure 1 Timeline of treatment pathway. IOL, intraocular lens.

(IOL). Of the six surgeries done before 6 months of age, half (Olivia, James and Jack) remained aphakic and used a contact lenses rather than IOLs. Each family that used contact lenses described it as the most distressing part of their experience, with two of the three families describing traumatic events related to inserting, removing and/or losing contact lenses. Patching experience ranged from none (including children with bilateral cataracts who had equal visual acuity loss in both eyes, and children with unilateral cataract who were given a very poor prognosis), to 4 hours per day over several years (Olivia, Oliver, Grace and Hannah). The most challenging aspect of care was described as patching, only superseded by use of contact lenses in infancy in the small subset of children for whom it was required.

\section{Phenomenological summary}

Three themes and several subthemes emerged from the phenomenological analysis related to how the medical

\section{Box 1 Summary of themes and subthemes}

1. Detection and diagnosis

a. Red reflex exam at birth

b. Referrals and process

2. Communication with medical community

a. Rapport

b. Provision of information about cataract and deprivation amblyopia

c. Foresight about treatment pathway

3. Social support

a. Advice from social networks

b. Availability of emotional and practical support system might better mitigate parental distress and encourage adherence. These are summarised in box 1 .

\section{Detection and diagnosis}

The detection and diagnosis of a cataract was a complex experience for families. If parents understood the timing of diagnosis to be linked to their child's visual outcome, emotions related to perceived efficiency of the screening and processes surrounding referral were heightened. Specifically, for those parents who were informed about the cataract promptly, the negative emotions related to an unexpected diagnosis were balanced by deep appreciation. By contrast, delays associated with perceived error elicited anger and distrust in the medical community.

Table 1A highlights the important role of midwives in early screening with the red reflex test; while Lily's mother expresses appreciation for prompt detection (left), Jack's mother expresses anger about a perceived missed detection (right). Table 1B highlights the importance of the process from detection to diagnosis. Olivia's mother was impressed with the prompt referral pathway and communication between medical staff (left), whereas Riley's mother expressed anger that the medical community had not appropriately referred her son to a specialist (right).

These experiences suggest that any strategy to improve medical provision for childhood cataracts in NZ needs to start with improved training for midwives, general practitioners and paediatricians, both in terms of administering the red reflex test and procedures for prompt referral. Anger with a representative of the medical community, exemplified by Jack and Riley's mother's comments, but shared by many informants, had a lasting impact. A 
Table 1 Improved detection and diagnosis

A: Red reflex screening test

She's been a midwife for ages, and because of that experience, she picked up it. (Lily's mother)

B: Referrals and process

We got sent to a follow up...to test the red eye reflex in the left eye and basically look in detail because they were expecting the possibility of a cataract. So it was diagnosed pretty much right from the start, she would have been about two days old when it was found and diagnosed. (Olivia's mother)
We were pretty angry at our midwife because we felt that she should have picked that up. (Jack's mother)

She [Allied medical worker] put him on a wait list and it took until about 15 months, it was a long time, so I was thinking I guess it's not a big deal. ... when we saw [ophthalmologist] he basically outlined right from the beginning that there was no hope. I found it ... sorry ... there is still a bit of anger there. (Riley's mother)

Examples of positive (left column) and negative (right column) experiences relating to timing of diagnosis.

parent's perception of a delay in diagnosis compromised trust in the medical community, which hindered ongoing communication.

\section{Communication with the medical community}

Once diagnosed, the relationship a family had with the specialist, and to a lesser degree, the allied medical staff, was an important part of their experience, permeating across treatment events. While some families lit up when describing the kindness and competence displayed by the medical professionals they had come to know well, others relived the anger and frustration when reflecting on their interactions with the medical community. Rapport between the parents and the specialist appeared to be particularly important, as it formed the foundation of the

\section{Table 2 Communicating with medical community}

\section{A: Building rapport}

We went in and met the paediatric ophthalmologist and he was just a lovely, lovely man. Yeah, it was just great (Aiden's mother)

I don't want to go to [...] anymore. He's quite 'nothing can be done, nothing can be done' (Riley's mother)

B: Provision of information about cataract and deprivation amblyopia

Asked whether specialist's I was avoiding the surgery description of the condition from when she was made sense to her: Yes, it threemonths onwards [...] did. Otherwise we could they were not answering never have agreed to the questions that I was asking surgery (Lily's mother) to my satisfaction (Emily's mother)

C: Foresight about the treatment pathway
When she was first diagnosed, the specialist sat us down with this one week old baby and said this is going to be a long, hard road (Olivia's mother)

Why hadn't (paediatric ophthalmologist) told us about this? We'd been going for three months! [...] It's not smooth, it's not transparent, and that's what's hard (Oliver's mother)
Examples of positive (left column) and negative (right column) experiences relating to communication. ongoing relationship with the medical team. If there was a connection made and trust established (table 2A, left) discourse was positive, whereas if a family was put off by the specialist (table $2 \mathrm{~A}$, right) the treatment pathway was impaired if not halted.

Beyond rapport, provision of understandable information about the condition was critical. What level of information was understandable varied between informants. Some families had a scientific background, and could appreciate a detailed technical explanation while others had limited background knowledge. Across this spectrum of varied backgrounds, effective communication allowed sufficient understanding for the family to feel comfortable with recommendations. In table $2 \mathrm{~B}$ we provide examples of two informants for whom understanding of the condition directly influenced uptake of surgery.

Appropriate, understandable communication was also important for parents to prepare for potential future events. When families became exasperated with homebased aspects of treatment, those who were prepared in advance (table 2C, left) were more resilient to the setbacks. On the other hand, families who had not anticipated the challenges, or were not provided useful information to face these challenges in advance (table 2C, right) became increasingly distressed by them, and lost trust in the system.

Whether the communication between the medical community and the parent was perceived as positive was individualised and nuanced, but across participants it included aspects of rapport, clear communication about the condition and of upcoming potential challenges.

\section{Social support}

Throughout the interviews, it became apparent that provision of care improved if the family's social context supported medical recommendations. This includes perspectives or values held by an individual family and the resources available to them. Advice that parents received from friends or family was an important part of their social context. Families whose social networks encouraged them to engage with the medical system were likely to move forward with recommendations (example in table $3 \mathrm{~A}$, left). On the other hand, some social networks 
Table 3 Social support

\section{A: Advice from social networks}

Her grandfather, who is a GP, saw that she was looking at things close and her eye was turning in. We took her to an optometrist and they picked up that there was something there, and they referred us to the ophthalmologist who said 'yes that looks like a cataract to me, we'll send you to [city]' And that all happened really quickly (Grace's mother)

\section{B: Availability of emotional and practical support}

When describing decision to go through with the surgery four years after it was recommended: It was just talking about it I guess with the [Community worker] that I was having the get-togethers with [...] she was lovely. I would talk with her and we would talk with [child] and she would even offer to drive us out there and stuff like that. Because that was another issue, just the transport (Emily's mother)
The doctor is trying to give us good advice [...] the sooner we get it done the better. And my mum and dad are pretty much saying 'No'. So that was another kinda difficulty [...] Yeah, an emotional, mental thing as well with the family's input-what they think about it (Lily's mother)
We took him to the hospital and they were saying right then and there to do a little surgery [...] I was carrying [another child], and my husband didn't want him to have the surgery (Benjamin's mother)

Examples of positive (left column) and negative (right column) experiences relating to social support.

were sceptical of the medical community, making it difficult or distressing for parents to seek, or act on, medical advice. Families who felt tension between the advice from the medical community and the advice from friends and family experienced an increased burden during an already challenging time (table $3 \mathrm{~A}$, right).

Beyond social networks advising with or against medical advice, there was an important emotional and practical role for this extended group. It was not specifically stated that a phone call from a friend, or an offer to baby-sit other children directly mitigated distress or delays along the treatment pathway, but the absence of this type of support appeared to be associated with both. For example, Benjamin's mother wanted to go through with cataract removal surgery, however, she was pregnant and did not have practical or theoretical support from her family network to have her son go through with the surgery (table 3B, right). Like Benjamin's mother, Emily's mother initially declined surgery. However, she was able to revisit this decision when she had more emotional and practical support (table 3B, left). Families were almost ubiquitously overwhelmed at some point during diagnosis or during amblyopia treatment, and only some had the emotional and practical support they needed to follow through with recommendations. It is of particular note that contact lens use required additional practical support; Olivia and Jack's families described requiring two or more adults to extract the contact from their infant's eye. Both families had excellent adherence at all stages of the treatment pathway, and substantial support networks.

As discussed within the second theme concerning communication, the family's social context also varied widely across informants. It was further complicated with changes over time; a school or job change, for example, impacted the balance of needs and resources a family had. To fully comply with recommendations, parents needed to have the resources to cope with new challenges, advocate for their child and be creative in their implementation of home-based treatments. Supportive social networks appeared critical to meet this high bar.

\section{DISCUSSION}

The goal of our descriptive phenomenological approach $^{47-49}$ was to develop an in-depth appreciation of the individual experience of childhood cataract treatment; with a specific interest in understanding sources of distress which (1) could be addressed by the medical community and (2) related to adherence to medical recommendations.

\section{Strengths and limitations}

We were able to recruit a wide variety of participants, with a diverse range of experiences despite childhood cataract being relatively rare. We found some informants were very appreciative of the medical community, while others felt as though they were let down. This diversity allowed us to identify themes and construct meaningful summaries which could be presented in positive and negative terms. In other words, for each potential factor, we could consider whether the lack impaired a family's experience, and the presence enhanced it. In some cases, this directly linked to whether a family adhered to medical recommendations. In this way, the diversity of informant experience is likely to aid in the quality and the generalisability of our analysis.

However, there were some limitations in our design and analysis. The phenomenological approach does not prioritise counting the frequency with which certain experiences occur. However, it is of interest to know, for example, how often parents decline available cataract surgery, or how many families were able to comply with occlusion therapy. We addressed this briefly by including such details in our 'narrative summary' and figure 1 . However, such quantitative questions are best answered with a different methodology. Conversely, a limitation 
could be that we did not go deep enough into respondents' experiences. For example, during the interviews we did not focus specifically on cultural frameworks for health. On iterative reflection, it was our impression that a deeper understanding of cultural differences in beliefs about well-being may have facilitated our understanding of informant's experiences. Further expanding on this, perhaps a symbolic interactionism theoretical perspective would be a valuable direction for future research in order to understand underlying cultural reasons for choices. Furthermore, we started with the perspectivethat adherence with ophthalmological recommendations is the best for children. Therefore, discussion around whether a parent's decision to decline surgery or cease patching was in fact best for the child was outside the scope of this project. Similarly, parental motivation was not a focus of our analysis, but is part of the theoretical framework related to adherence. ${ }^{51}$ Following up on these points could enhance future research.

\section{Summary and implications of findings}

The varied experiences of the diverse informants we interviewed revealed opportunities for systemic improvement in childhood cataract treatment. Early detection and prompt medical treatment are critical for good visual outcomes. ${ }^{21}{ }^{22}$ Delayed detection was a perceived issue for many of our informants. More effective implementation of the red reflex examination may improve this situation. ${ }^{18} 29$ Survey data from practitioners in NZ reflected this opportunity for improvement, specifically highlighting the value of better training for those administering early eye examinations. ${ }^{30}$ Our work supports the value of such an initiative.

Addressing issues that are social rather than organisational is perhaps more complex. The experiences expressed by our informants suggest that improved communication between the patient's families and the healthcare community, and promoting strong social support networks are particularly important. These are not new ideas. Literature concerned with chronic paediatric conditions has described similar phenomena. For example, Shudy et $a \tilde{l}^{2}$ highlighted the importance of a 'sense of partnership with the staff' mirroring the second emergent theme in our analysis. Similarly, Jackson et $a \tilde{l}^{\tilde{3}}$ discuss how close social support networks improve coping in families of children with brain tumours, with ideas closely related to our third theme of social support. Within our cohort, the impact of these factors was most dramatic in relation to uptake of surgical services. Within the themes of communication and social support, the specific concerns these families raised reflect barriers experienced in lower resources areas. These include indirect costs such as travel, ${ }^{31}{ }^{41}$ lack of appropriate information, ${ }^{1131}$ beliefs about health ${ }^{31}$ and/or the parent targeted for education not having decisional power. ${ }^{31}$

In addition to these poignant cases in which surgery was declined, additional families in our cohort felt overwhelmed at other stages of the treatment pathway, particularly when attempting patching and contact lens wear (struggles more consistent with the literature from higher resourced countries). Contact lens use in infants (and to a lesser degree patching) has been associated with higher levels of parental stress. ${ }^{33}$ Parental stress is known to contribute to decreased adherence with amblyopia treatment in cases of strabismic and anisometropic amblyopia. ${ }^{37}$ These ideas appeared to be consistent with accounts from our informants. Again, good communication and strong social support appeared to mitigate these factors. Although care must be taken when generalising, we suggest that perhaps communication and practical support are factors which account for the difference between the results of Drews $e t a l^{33}$ (which revealed an association between the use of contact lenses following paediatric cataract surgery and parental stress) and those of Celano $e t a \hat{l}^{2}$ (which did not). Notably, the data reported by Celano $e t a l^{32}$ were collected in the context of a clinical trial, in which extensive information and practical support were provided.

Although all families found parts of the treatment pathway challenging at times, cultural and socioeconomic factors appeared to exacerbate the challenges. Some work suggests that if a family does not feel connected with the dominant society (or the person representing the society as the medical professional), their child is less likely to adhere to treatment for amblyopia. ${ }^{38}$ In our diverse cohort the concept appeared to extend beyond patching to cataract removal, which has more substantial consequences. Although there were many professionals involved in patient care, paediatric ophthalmologists were generally seen as the primary providers of information. This means the demand on a single specialist to provide sensitive, individualised support to a diverse community may be significant.

In some cases, print materials can help supplement communication of important information and encourage treatment compliance, ${ }^{36}$ however, information alone is often insufficient to promote action. ${ }^{54}$ Patient care may benefit from the provision of accurate information and practical support from different professionals. Some research has described the role of a "childhood blindness coordinator' to be particularly beneficial to fill this gap. ${ }^{45}$ This role can involve helping parents understand the condition, providing foresight about the treatment pathway, as well as providing practical support such as text message reminders and travel planning. ${ }^{55}$ In terms of emotional support, formal networks tend to be less effective than informal support networks. ${ }^{53}$ However, Ireys $e t$ $a l$ showed the benefit of peer support groups for mothers of children with chronic illness, ${ }^{56}$ and Emily's family provides a good example of how a caring community volunteer can provide effective support. Research within childhood disability services in NZ has suggested the role of a 'cultural case worker' may facilitate both improved communication and supplement social support for families with culturally or linguistically diverse backgrounds, ${ }^{57}$ working as 'patient advocates' rather than expert medical 
staff. These are all avenues that could be further explored to help families dealing with childhood cataract.

Although the system for childhood cataract treatment in NZ is technically robust, it does not appear to have sufficient support for families who are unable to effectively advocate for themselves. The current study suggests strategies from research in lower income countries may help some NZ families. Examples are the community roles of 'key informants' and 'childhood blindness coordinators', which facilitate education, detection process, communication and social suport. NZ has organisations that could fill these roles, such as the Blind and Low Vision Network New Zealand, (which provides comprehensive support for children, from infancy to 17 years of age, with moderate to severe visual impairment) and social workers or caseworkers. However, their services are not well used by families due to the lack of awareness among general population and medical practitioners. Better training for midwives, paediatricians and general practitioners for early detection and referral as well as better awareness of existing support services are likely to be important steps towards improving provision of care for childhood cataract.

\section{CONCLUSION}

Childhood cataract is a rare and challenging condition, ${ }^{15} 1626$ its treatment requires much from families during what is often already an overwhelming phase of life. Our work suggests that availability of surgery and funding for secondary costs for those who need it is insufficient to achieve the best visual outcomes for all NZ children with cataracts. We need to improve screening practices, including streamlining referral pathways to specialised paediatric ophthalmologists. We need to find ways to communicate effectively with diverse families, ensuring the condition and its treatment is understood and family's questions are answered. Finally, we need to consider creative ways to support families with surgical uptake and postsurgical follow-up. This requires awareness of family context, including available emotional and practical support.

Acknowledgements We would like to thank all the families who took the time to talk to us about thier experiences, as well as David Welch for his early contributions to the project.

Contributors LMH, JMB, SD and BT designed the study. LMH and SD recruited the participants. LMH conducted the interviews and transcibed the data. KAB and LMH independently coded and analysed the transcribed data, and then interpreted the data in an iterative manner. LMH wrote the first draft the manuscript, and all authors assisted with revisions. All authors were involved in the final proofing process and agreed to be accountable for the content of the manuscript.

Funding LMH was supported financially by a scholarship from Education New Zealand to complete this work.

Disclaimer Education New Zealand had no role in data collection, interpretation or reporting.

Competing interests None declared.

Patient consent Parental/guardian consent obtained.
Ethics approval The study complied with the tenets of the Declaration of Helsinki and was approved by ethics committees from the University of Auckland and the Auckland District Health Board.

Provenance and peer review Not commissioned; externally peer reviewed.

Data sharing statement Full transcripts of interviews are not available to protect participants' anonymity.

Open access This is an open access article distributed in accordance with the Creative Commons Attribution Non Commercial (CC BY-NC 4.0) license, which permits others to distribute, remix, adapt, build upon this work non-commercially, and license their derivative works on different terms, provided the original work is properly cited, appropriate credit is given, any changes made indicated, and the use is non-commercial. See: http://creativecommons.org/licenses/by-nc/4.0/.

\section{REFERENCES}

1. Gilbert C, Foster A. Childhood blindness in the context of VISION 2020--the right to sight. Bull World Health Organ 2001;79:227-32.

2. Courtright $P$, Hutchinson AK, Lewallen $S$. Visual impairment in children in middle- and lower-income countries. Arch Dis Child 2011;96:1129-34.

3. Gogate P, Dole K, Ranade S, et al. Cost of pediatric cataract surgery in Maharashtra, India. Int J Ophthalmol 2010;3:1248-52.

4. Shamanna BR, Muralikrishnan R. Childhood cataract: magnitude, management, economics and impact. Community Eye Health 2004;17:17-18

5. Evans CT, Lenhart PD, Lin D, et al. A cost analysis of pediatric cataract surgery at two child eye health tertiary facilities in Africa. $J$ Aapos 2014;18:559-62.

6. Rahi JS, Dezateux C. British Congenital Cataract Interest Group. Measuring and interpreting the incidence of congenital ocular anomalies: lessons from a national study of congenital cataract in the UK. Invest Ophthalmol Vis Sci 2001;42:1444-8.

7. Kalia A, Gandhi T, Chatterjee G, et al. Assessing the impact of a program for late surgical intervention in early-blind children. Public Health 2017;146:15-23.

8. Sinha P, Chatterjee G, Gandhi T, et al. Restoring vision through "Project Prakash": the opportunities for merging science and service. PLoS Biol 2013;11:e1001741.

9. Levine S, Øverland L, Ramson P. The miracle workers: obstacles and opportunities for restoring sight to children in KwaZulu-Natal. Anthropology Southern Africa 2014;37(1-2):81-93.

10. Lewallen S, Schmidt E, Jolley E, et al. Factors affecting cataract surgical coverage and outcomes: a retrospective cross-sectional study of eye health systems in sub-Saharan Africa. BMC Ophthalmol 2015;15:67.

11. Courtright P. Childhood cataract in sub-Saharan Africa. Saudi $J$ Ophthalmol 2012;26:3-6.

12. Kemmanu V, Hegde K, Giliyar SK, et al. Prevalence of Childhood Blindness and Ocular Morbidity in a Rural Pediatric Population in Southern India: The Pavagada Pediatric Eye Disease Study-1. Ophthalmic Epidemiol 2016;23:185-92

13. Rahi JS, Cable N; British Childhood Visual Impairment Study Group. Severe visual impairment and blindness in children in the UK. Lancet 2003;362:1359-65.

14. Koay CL, Patel DK, Tajunisah I, et al. A comparative analysis of avoidable causes of childhood blindness in Malaysia with low income, middle income and high income countries. Int Ophthalmol 2015;35:201-7

15. Medsinge A, Nischal KK. Pediatric cataract: challenges and future directions. Clin Ophthalmol 2015;9:77-90.

16. Oscar A, Veleva N, Chernodrinska V, et al. Childhood cataract. Pediatriya 2014;54:58-61.

17. Lewallen $\mathrm{S}$, Roberts $\mathrm{H}$, Hall $\mathrm{A}$, et al. Increasing cataract surgery to meet Vision 2020 targets; experience from two rural programmes in east Africa. Br J Ophthalmol 2005;89:1237-40.

18. Litmanovitz I, Dolfin T. Red reflex examination in neonates: the need for early screening. Isr Med Assoc J 2010;12:301-2.

19. Shija F, Shirima S, Lewallen S, et al. Comparing key informants to health workers in identifying children in need of surgical eye care services. Int Health 2012;4:1-3.

20. Baden C, Shija F, Lewallen S, et al. Glaucoma after pediatric cataract surgery in a population with limited access to care. J Aapos 2013;17:158-62.

21. Birch EE, Cheng C, Stager DR, et al. The critical period for surgical treatment of dense congenital bilateral cataracts. J Aapos 2009;13:67-71. 
22. Birch EE, Stager DR. The critical period for surgical treatment of dense congenital unilateral cataract. Invest Ophthalmol Vis Sci 1996;37:1532-8.

23. Holmes JM, Clarke MP. Amblyopia. The Lancet 2006;367:1343-51.

24. Hamm LM, Black J, Dai S, et al. Global processing in amblyopia: a review. Front Psychol 2014;5:583.

25. Wang J. Compliance and patching and atropine amblyopia treatments. Vision Res 2015;114:31-40.

26. Repka MX. Monocular infantile cataract: treatment is worth the effort. Arch Ophthalmol 2010;128:931-3.

27. Saiju R, Yun S, Yoon PD, et al. Bruckner red light reflex test in a hospital setting. Kathmandu University Medical Journal 2012;10:23-6.

28. Gräf M. Early detection of ocular disturbances in children. Brückner's transillumination test (red reflex) - A must in childhood screening. Deutsches Arzteblatt 2007;104:724-9.

29. Fry M, Wilson GA. Scope for improving congenital cataract blindness prevention by screening of infants (red reflex screening) in a New Zealand setting. J Paediatr Child Health 2005;41:344-6.

30. Raoof N, Dai S. Red reflex screening in New Zealand: a large survey of practices and attitudes in the Auckland region. $N Z$ Med $J$ 2016;129:38-43

31. Bronsard A, Geneau R, Shirima S, et al. Why are children brought late for cataract surgery? Qualitative findings from Tanzania. Ophthalmic Epidemiol 2008;15:383-8.

32. Celano M, Hartmann EE, Drews-Botsch CD; Infant Aphakia Treatment Study Group. Parenting stress in the infant aphakia treatment study. J Pediatr Psychol 2013;38:484-93.

33. Drews C, Celano M, Plager DA, et al. Parenting stress among caregivers of children with congenital cataracts. J Aapos 2003;7:244-50.

34. Drews-Botsch CD, Celano M, Kruger S, et al. Adherence to occlusion therapy in the first six months of follow-up and visual acuity among participants in the Infant Aphakia Treatment Study (IATS). Invest Ophthalmol Vis Sci 2012;53:3368-75

35. Drews-Botsch CD, Hartmann EE, Celano M; Infant Aphakia Treatment Study Group. Predictors of adherence to occlusion therapy 3 months after cataract extraction in the Infant Aphakia Treatment Study. J Aapos 2012;16:150-5.

36. Loudon SE, Fronius M, Looman CW, et al. Predictors and a remedy for noncompliance with amblyopia therapy in children measured with the occlusion dose monitor. Invest Ophthalmol Vis Sci 2006;47:4393-400

37. Loudon SE, Passchier J, Chaker L, et al. Psychological causes of non-compliance with electronically monitored occlusion therapy for amblyopia. Br J Ophthalmol 2009;93:1499-503.

38. Tjiam AM, Akcan H, Ziylan F, et al. Sociocultural and psychological determinants in migrants for noncompliance with occlusion therapy for amblyopia. Graefes Arch Clin Exp Ophthalmol 2011;249:1893-9.

39. Castañeda YS, Cheng-Patel CS, Leske DA, et al. Quality of life and functional vision concerns of children with cataracts and their parents. Eye 2016;30:1251-9.

40. Courtright P, Bowman R, Gilbert C, et al. Childhood cataract in Africa, 2008.
41. Lenhart PD, Courtright P, Wilson ME, et al. Global challenges in the management of congenital cataract: proceedings of the 4th International Congenital Cataract Symposium held on March 7, 2014, New York, New York. J Aapos 2015;19:e1-e8.

42. Sturman D. Blindness in childhood in New Zealand. Trans Ophthalmol Soc N Z 1975;27:45-52.

43. Chong C, Dai S. Cross-sectional study on prevalence, causes and avoidable causes of visual impairment in Māori children. New Zealand Medical Journal 2013;126:1379.

44. Hamm L, Chen Z, Li J, et al. Interocular suppression in children with deprivation amblyopia. Vision Res 2017;133:112-20.

45. Hamm LM, Chen Z, Li J, et al. Contrast-balanced binocular treatment in children with deprivation amblyopia. Clinical and Experimental Optometry 2018;101:541-52.

46. Starks H, Brown Trinidad S. Choose Your Method: A Comparison of Phenomenology, Discourse Analysis, and Grounded Theory. Qual Health Res 2007;17:1372-80.

47. Husserl E. Ideas: General introduction to pure phenomenology. New York: Collier Books, 1962.

48. Giorgi A. Psychology as a human science: A phenomenologically based approach. New York: Harper \& Row, 1970.

49. Wertz FJ. A phenomenological psychological approach to trauma and resilience. Five Ways of Doing Qualitative Analysis. New York: The Guildford Press, 2011.

50. O'Brien BC, Harris IB, Beckman TJ, et al. Standards for reporting qualitative research: a synthesis of recommendations. Academic medicine: journal of the Association of American Medical Colleges 2014;89:1245-51.

51. McGrady ME, Ryan JL, Brown GA, et al. Topical review: Theoretical frameworks in pediatric adherence-promotion interventions: Research findings and methodological implications. J Pediatr Psychol 2015;40:721-6.

52. Shudy M, de Almeida ML, Ly S, et al. Impact of pediatric critical illness and injury on families: a systematic literature review. Pediatrics 2006;118 Suppl 3(Supplement_3):S203-S218.

53. Jackson AC, Enderby K, O'Toole M, et al. The role of social support in families coping with childhood brain tumor. J Psychosoc Oncol 2009;27:1-24.

54. Blödt S, Kaiser M, Adam Y, et al. Understanding the role of health information in patients' experiences: secondary analysis of qualitative narrative interviews with people diagnosed with cancer in Germany. BMJ Open 2018;8:e019576.

55. Kishiki E, van Dijk K, Courtright P. Strategies to improve followup of children after surgery for cataract: findings from Child Eye Health Tertiary Facilities in sub-Saharan Africa and South Asia. Eye 2016;30:1234-41.

56. Ireys HT, Chernoff R, DeVet KA, et al. Maternal outcomes of a randomized controlled trial of a community-based support program for families of children with chronic illnesses. Arch Pediatr Adolesc Med 2001;155:771-7.

57. Mortensen A, Latimer S, Yusuf I. Cultural case workers in child disability services: an evidence-based model of cultural responsiveness for refugee families. Kòtuitui: New Zealand Journal of Social Sciences Online 2014;9:50-9. 